\title{
A Conceptual Model to Optimize Operating Cost of Passenger Ships in Macau
}

\author{
Xin-long Xu, ${ }^{1}$ Lai Leng Iao, ${ }^{2}$ Yanting Yin, ${ }^{2}$ Silu Chen, ${ }^{3}$ and Yujie Chen ${ }^{4}$ \\ ${ }^{1}$ College of Business, Hunan Agricultural University, Changsha 410128, China \\ ${ }^{2}$ School of Business, Macau University of Science and Technology, Taipa, Macau \\ ${ }^{3}$ School of Management, Wuhan University of Technology, Wuhan, Hubei 430070, China \\ ${ }^{4}$ Faculty of Hospitality and Tourism Management, Macau University of Science and Technology, Taipa, Macau
}

Correspondence should be addressed to Yujie Chen; yjchen@must.edu.mo

Received 11 July 2014; Revised 16 March 2015; Accepted 23 March 2015

Academic Editor: Christopher Pretty

Copyright (C) 2015 Xin-long Xu et al. This is an open access article distributed under the Creative Commons Attribution License, which permits unrestricted use, distribution, and reproduction in any medium, provided the original work is properly cited.

To facilitate more convenient travel as the economy of Macau expands, the government of Macau has allowed shipping companies to add passenger ships and shipping lines. This paper demonstrates how shipping companies can reduce costs by optimizing passenger ships and crew size. It analyzes operating conditions for each shipping depot, including transit time, ships, and volume of passengers. A series of integer programming models is proposed. After a practical demonstration using Excel to solve the LP model, we show that the reduction in the number of passenger ships and crew size could reach $22.6 \%$ and $29.4 \%$, respectively.

\section{Introduction}

Commercial shipping is essential to economic development [1]. It has a history dating back 2000 years. Global trade relies on ships to transport cargoes and conduct economic exchange activities.

The economy of Macau has remained one of the most open in the world since control reverted to China in 1999. It grew $13.1 \%$ annually from 2006 to 2012 [2]. The government's budget returned a surplus after 2002 because of a surge in visitors from mainland China and a hike in taxes on gambling profits. Tourism geared towards gambling is the backbone of Macau's economy. Taxes on gambling profit generate $70 \%$ of government revenue. Due to the opening of new hotel casinos and easing of travel restrictions, the number of visitors from mainland China has risen from 9.1 million in 2000, to 28.2 million in 2011 [3]. Macau is expected to receive between 30 and 31 million visitors in 2014 [4]. In 2007, German travel trade members of Go Asia chose Macau as the most promising future tourism destination in Asia [5]. Even now Macau is rated as one of the world's top tourism destinations by the World Tourism Organization [6].

Since the Sands and Wynn casinos opened in 2003, more shuttle buses have been put in service, leading to greater traffic pressure in Macau. To provide faster and more convenient travel for visitors, the Macau SAR has allowed shipping companies to scale up by increasing the number of passenger ships and shipping lines. Shipping companies now need to purchase more ships and employ more crews to take advantage of the new business opportunities.

To maintain profitability, shipping companies must minimize the operating costs of passenger ships. To assist them with achieving this objective, a series of integer programming models is proposed to optimize the fleet and crew size of passenger ships. The reduction of the passenger ship fleet and crews could reach $22.6 \%$ and $29.4 \%$, respectively. This paper enriches the theory and practice surrounding operating cost minimization for ships. The next section reviews relevant literature. Methodology and a case study are discussed in Section 3. Discussion and conclusions are provided in the last section.

\section{Literature Review}

Christiansen et al. [7] categorized the existing literature about ship routing and scheduling as follows:

(1) Strategic planning-design of optimal fleets and maritime supply chains. 
(2) Tactical and operational problems in industrial shipping.

(3) Tactical and operational problems in tramp shipping.

(4) Tactical and operational problems in liner shipping.

(5) Naval routing and scheduling.

(6) Other related shipping problems.

They reviewed the literature on ship routing and scheduling and discussed problems during the new millennium [8]. They provide four basic models in this area:

(1) Liner shipping.

(2) Industrial and tramp shipping.

(3) Sailing speed, bunkering and emissions.

(4) Offshore logistics, lightering, and stowage, respectively.

In this paper, we focus on the optimization of fleet and crew in Macau. This problem includes fleet size and composition, ship routing, scheduling, and network design. In some aspects, this problem is similar to Christiansen's model (1), but we include some new circumstances in this paper that they have not discussed $[7,8]$.

Dantzig and Fulkerson [9] dealt with minimizing the number of tankers needed to perform a given set of schedules. Since there was only one type of vessel in this problem, it was a fleet sizing and transportation problem. An integer linear programming model was designed by Jaramillo and Perakis [10] to optimize shipping lines considering the integration of ports, lines, and vessels based on a freight O-D matrix. Cho and Perakis [11] analyzed the fleet size for a container liner company and optimized the shipping lines, through setting up alternative lines for different containers, and solved the problem with a linear programming model (mixed integer planning). Fagerholt [12] studied the optimization of a container vessel fleet used to serve Norwegian coastal lines. Bendall and Stent [13] proposed a model to determine the optimal number of ships and a fleet deployment plan in a container ship hub and spoke application. $\mathrm{Ng}$ and Kee [14] simulated the optimal container ship sizes from the perspective of ship operators. Meng and Wang [15] proposed a model that considers uncertainty in container shipment demand. It was assumed that the demand between any two ports follows a normal distribution. They imposed chance constraints for each liner service route in order to guarantee that the ships assigned to that route could satisfy the demand with a given probability. Crary et al. [16] described a special problem about the size of the destroyer fleet, which used quantitative methods and expert opinions. Ting and Tzeng [17] used detailed costs and time information to schedule a fixed nine-port circular line by dynamic programming. Lai and Lo [18] formulated a ferry network design problem by considering the optimal fleet size, routing, and scheduling for both direct and multistop services. The objective function they presented combines both the operators' and passengers' performance measures. Fagerholt [19] designed short routes for a fleet of ships such that each ship repeats its sailing every week. The model he proposed had one common loading depot and many discharging ports. A ship could sail several routes in a week if it had time to complete all the routes sequentially. The real problem had 15 ports and five ships, while his largest test problem had 40 ports and 20 ships. Richir et al. [20] used the LBR-5 software to optimize ship structures according to objectives of higher inertia, less weight, or lower cost. The criterion offered the choice between two calculation approaches. The first was based on a simplified assessment of cost. The second calculated cost based on data specific to the shipyard. The material cost was analyzed according to the first approach while the cost of the labor considered each relevant operation of the shipbuilding with respect to the LBR-5 model. Zeng and Yang [21] described a case study on developing a new ocean shipping system for coal transportation. They proposed an IP model using a tabu search heuristic to determine the optimal fleet and the routing of the vessels. Fagerholt et al. [22, 23] presented a decision support methodology for general strategic planning. They evaluated a set of strategic decisions through a simulation that incorporated optimization of the underlying ship routing and scheduling. The authors argued that this was one alternate application of their methodology, even though the case study shown in the paper did not include decisions regarding fleet size and composition. Fagerholt et al. [24] studied the fleet deployment problem for a RoRo shipping company. In their model, each ship was modeled individually with a given initial open position and time of availability for new assignments. Each voyage was also modeled explicitly with a time window in which the voyage had to start. Tests indicated that they achieved $2-10 \%$ improvements over the shipping company's manual planning. Zacharioudakis et al. [25] included sailing speed as a decision variable and showed how their method could be used for what-if analysis for various demand scenarios. Another study dealing with fleet deployment was by Liu et al. [26]. They presented a joint model for container flow management and fleet deployment. The model they proposed was tested on a small sample. Alvarez et al. [27] proposed a MIP model for the multiperiod fleet composition and deployment problem and extended it into a robust optimization model to deal with demand uncertainty. The model assisted shipping companies with decisions regarding the sale, purchase, chartering in and out, lay-up, and scrapping of ships, as well as the deployment of the active ships to contracts and geographic markets.

Most of the literature discussed large ships and container ships. Few authors focused on optimization of passenger ships, especially optimization of the fleet size of passenger ships and crews. Because passenger ships in Macau are operated by casinos, serving their clients for the most part, they emphasize service and client satisfaction. Therefore, the operation of passenger ships should be optimized under the premise that the client satisfaction is met first, followed by operating cost. Through a series of LP models, this paper optimizes the fleet size of passenger ships and crews under the premise that the service level is maintained to reduce the operating cost of passenger ships. 


\section{The Operating Background}

3.1. Details of Operating Background. Various locations in Macau suffer from serious traffic congestion during peak periods. Excessive bus trips, larger buses, and free casino shuttle buses lead to serious disruption of traffic flow. Rapid growth in the number of vehicles has challenged road capacity. As of the end of last year, the number of motor vehicles in Macau totaled more than 230,000 and continues to grow at an amazing rate. The number of vehicles has increased by over $60 \%$ during the past ten years, while due to limited land area, growth in the road system has been less than $20 \%$. According to data from Cartography and Cadastre Bureau, in 2004 there were only 362 kilometers in the road system, and this increased to 422 by the end of 2014. Addressing the issue of vehicle congestion with road expansion is not feasible. Adding other means of public transportation such as passenger ships featuring large capacity, low price, and short running time is a better way to ease traffic congestion.

The Macau government has advocated an increase in water transport as one of several measures to ease the pressure on land transportation. With the special problems of Macau in mind, this paper puts forward a series of LP models to optimize the fleet size of passenger ships and crews, to satisfy passenger satisfaction regarding waiting time traveling to and from Hong Kong, Guangzhou, Shenzhen, and Macau, and to reduce operating costs.

3.2. Depot Selection. Over 150 sea-crossing services are scheduled daily between Macau and Hong Kong [28]. These routes are served by high speed catamarans (capacity 415 passengers) and jetfoils (capacity 260 passengers). The catamaran has larger capacity and higher speed and is cheaper to operate, so most companies use it as their main vessel. In this paper, we set the number of seats on catamarans as a constant in the LP model for convenience. The journey takes one hour one way. There are also daily scheduled ferry services between Macau and Shenzhen. These services are operated by Turbo Jet (from Sheung Wan) and New World First Ferry Macau (from Tsim Sha Tsui). Cotai Jet also operates between Taipa Temporary Ferry Terminal, the Hong Kong-Macau Ferry Terminal, and Hong Kong. There are also regular scheduled helicopter services between Hong Kong and Macau, operated by Heli Express. This trip takes 20 minutes. A new ferry terminal adjacent to the Macau International Airport is under construction. It will act as a major hub for passengers transferring between the Hong Kong International Airport and the Macau International Airport. Ferry services are also available from Macau to Wanzai and Zhuhai, China, taking less time than crossing between China and Macau by the land.

In Macau, there are two shipping depots, Ferry Terminal and Pac On Pier. 95\% of visitors arrive at Macau from seven depots: Sheung Wan (SW), Tsim Sha Tsui (TST), Tuen Mun (TM), International Airport of Hong Kong (IAHK), Shenzhen Airport (SA), Shekou (SK), and Guangzhou (GZ). These are the arrival points and destinations used for data collection.

\section{Optimizing the Fleet Size}

According to the data in Tables 1 and 2, in the following models, the passenger ships have a capacity of 415 seats and the tolerance limit for waiting time is set at 16.3 minutes. To ensure the validity of the model, we have used the number of visitors during the peak hours as the normal passenger flow for this study at the 7 depots and 2 depots of Macau.

4.1. Assumptions. In order to build an effective model to minimize the fleet size of the passenger ships in Macau, we make some assumptions as follows:

(i) The passenger demand for one shipping line is independent of demand for other lines.

(ii) The passenger demand is independent of the frequency of passenger ship departures.

(iii) The shipping speed is constant between two depots.

(iv) The types of passenger ships are uniform, and the capacity is fixed.

(v) The upper tolerance limit of the waiting time for passengers is set as 16.3 minutes.

\subsection{Definitions of Variables and Symbols}

(i) $Y=$ total passenger ships (PS).

(ii) $D_{2 k, 2 k+2}=$ PS from the depots of Macau to the depots of Shenzhen, Hong Kong, and Guangzhou during the time period [ $2 k, 2 k+2]$.

(iii) $A_{2 k, 2 k+2}=$ PS from the depots of Shenzhen, Hong Kong, and Guangzhou to the depots of Macau during the time period $[2 k, 2 k+2]$.

(iv) $M_{2 k, 2 k+2}=$ passengers that left Macau during the time period $[2 k, 2 k+2]$.

(v) $N_{2 k, 2 k+2}=$ passengers that arrived in Macau during the time period $[2 k, 2 k+2]$.

(vi) $C=$ seats provided by the PS.

(vii) $T_{1}=$ transit time of PS from the corresponding depots to Macau depots (including waiting time).

(viii) $T_{2}=$ transit time of PS from Macau depots to the corresponding depots (include waiting time).

(ix) $k=3, \ldots, 11 . k$ represents a constant and can be a value from 3 to $11 ;[2 k, 2 k+2]$ represents the working time from 6:00 a.m. and time period is 2 hours. When $k=11,2 k+2=24$.

4.3. Modeling and Explanation. The LPs model is developed as follows:

$$
\operatorname{Min} Y=D_{2 k, 2 k+2}+A_{2 k, 2 k+2}
$$

(1) PS departing from each Macau depot to the depots of Shenzhen, Hong Kong, and Guangzhou. This is the minimum number of departures during the two-hour period:

$$
D_{2 k, 2 k+2} \leq \operatorname{Max}\left\{2 * \frac{60}{16.3}, \frac{M_{2 k, 2 k+2}}{C}\right\} .
$$


TABLE 1: The largest passenger number at each depot.

\begin{tabular}{lcccc}
\hline \multirow{2}{*}{ Depots } & \multicolumn{2}{c}{ Ferry Terminal } & \multicolumn{2}{c}{ Pac On Pier } \\
& Departure & Arrival & Departure & Arrival \\
\hline SW & 1588 & 1287 & 887 & 766 \\
TST & 1363 & 1594 & 887 & 1636 \\
TM & 212 & 233 & 356 & 408 \\
IAHK & 455 & 476 & 508 & 540 \\
SA & 239 & 181 & 162 & 152 \\
SK & 497 & 658 & 551 & 468 \\
GZ & 386 & 271 & 126 & 204 \\
\hline
\end{tabular}

Note: SW, TST, TM, IAHK, SA, SK and GZ are short for Sheung Wan, Tsim Sha Tsui, Tuen Mun, International Airport of Hong Kong, Shenzhen Airport, Shekou, and Guangzhou respectively.

TABLE 2: The maximum transit time of PS between each depots.

\begin{tabular}{lcccc}
\hline \multirow{2}{*}{ Depots } & \multicolumn{2}{c}{ Ferry Terminal } & \multicolumn{2}{c}{ Pac On Pier } \\
& Departure & Arrival & Departure & Arrival \\
\hline SW & 68 & 65 & 72 & 75 \\
TST & 58 & 56 & 54 & 59 \\
TM & 66 & 72 & 67 & 62 \\
IAHK & 50 & 54 & 52 & 56 \\
SA & 68 & 70 & 60 & 59 \\
SK & 75 & 79 & 80 & 75 \\
GZ & 85 & 82 & 80 & 79 \\
\hline
\end{tabular}

Note: SW, TST, TM, IAHK, SA, SK, and GZ are short for Sheung Wan, Tsim Sha Tsui, Tuen Mun, International Airport of Hong Kong, Shenzhen Airport, Shekou, and Guangzhou, respectively.

(2) PS returning to each Macau depot from the depots of Shenzhen, Hong Kong, and Guangzhou. This is the minimum number of departures during the twohour period. This is similar to (1), but in the opposite direction:

$$
A_{2 k, 2 k+2} \leq \operatorname{Max}\left\{2 * \frac{60}{16.3}, \frac{N_{2 k, 2 k+2}}{C}\right\} .
$$

(3) PS from the Shenzhen, Hong Kong, and Guangzhou depots to the Macau depots depart at maximum intervals of 16.3 minutes:

$$
D_{2 k, 2 k+2} \geq \frac{\left[T_{1}+T_{2}\right]}{16.3} .
$$

(4) PS from Macau depots to the Shenzhen, Hong Kong, and Guangzhou depots depart at maximum intervals of 16.3 minutes. This is similar to (3), but in the opposite direction:

$$
A_{2 k, 2 k+2} \geq \frac{\left[T_{1}+T_{2}\right]}{16.3}
$$

where $D_{2 k, 2 k+2}, A_{2 k, 2 k+2}, M_{2 k, 2 k+2}, N_{2 k, 2 k+2} \in Z^{+}, k=$ $3, \ldots, 11$.
4.4. Collection of Data. The time period from 6:00 a.m. to $12: 00 \mathrm{p} . \mathrm{m}$. fits with the passenger ships' timetables and includes both peak and valley hours. To ensure validity, we selected the number of visitors during the peak holiday hours as the normal passenger flow. For convenience, we set a two-hour time period. Table 1 shows the passenger numbers at each depot, and Table 2 lists the maximum transit times between each depot.

We use a maximum waiting time of 16.3 minutes to maintain passenger service level. According to Shi et al. [29], this is the tolerance limit for waiting time. Longer waiting times would deter passengers from traveling by ship. While the capacity of the passenger ships varies among shipping companies, the average capacity is 415 seats based on previous studies in the field survey.

4.5. Computational Results. The model includes a series of LPs between each depot at nine different two-hour intervals. For the Ferry Terminal, optimal passenger ship population is developed as follows. First, we run the LP based on the largest passenger number and the maximum transit time between the Ferry Terminal and the seven depots, at nine two-hour time intervals. Second, for each depot, we select the maximum number of passenger ships that the Ferry Terminal provided to match the passenger demand all the day at each depot. Table 3 shows the optimal population of the passenger ships for each depot. We arranged 3, 4, 2, 3, 2, 3, and 2 passenger ships back and forth for the routes between Ferry Terminal and the seven destination depots, respectively. Finally, we concluded that the optimal number of passenger ships is 72 . The actual number of passenger ships currently under way is 93 . The discrepancy from optimal fleet size is significant at $22.6 \%$.

\section{Optimizing the Fleet Size of Passenger Ships Crews}

To reduce operating costs as much as possible, we need to optimize the crew size. According to passenger ship companies, the actual current crew size is 85 . To maintain service level, during holidays, they tend to employ more crew members. Crew members are classified as full-time or parttime employees. The optimal result will reduce the full-time crew and increase part-time crew size while meeting the demands of passengers during holidays.

\subsection{Assumptions}

(a) Full-time crew work from 9:00 a.m. to 9:00 p.m. One hundred six crew members are available. Occasionally, they take a one-hour lunch break from 11:30 a.m. to $12: 30$ p.m.

(b) Part-time crew work 6 consecutive hours with no lunch breaks. Occasionally, their working hours are between 6:00 a.m. to 24:00 p.m. Based on the optimal population of passenger ships, the minimal number of crew members for each period is shown in Table 4 . Working hours for part-time drivers cannot exceed 
TABLE 3: The optimal population of PS.

\begin{tabular}{lccccc}
\hline \multirow{2}{*}{ Depots } & \multicolumn{2}{c}{ Ferry Terminal } & \multicolumn{2}{c}{ Pac On Pier } & \multirow{2}{*}{ Total } \\
& Departure & Arrival & Departure & Arrival & \\
\hline SW & 3 & 3 & 3 & 3 & 12 \\
TST & 4 & 4 & 3 & 3 & 14 \\
TM & 2 & 2 & 2 & 2 & 8 \\
IAHK & 3 & 3 & 2 & 2 & 10 \\
SA & 2 & 2 & 2 & 2 & 8 \\
SK & 3 & 3 & 3 & 3 & 12 \\
GZ & 2 & 2 & 2 & 2 & 8 \\
Total & $\mathbf{1 9}$ & $\mathbf{1 9}$ & $\mathbf{1 7}$ & $\mathbf{1 7}$ & $\mathbf{7 2}$ \\
\hline
\end{tabular}

Note: SW, TST, TM, IAHK, SA, SK, and GZ are short for Sheung Wan, Tsim Sha Tsui, Tuen Mun, International Airport of Hong Kong, Shenzhen Airport, Shekou, and Guangzhou, respectively.

281 or $50 \%$ of the day's minimum requirement [ $71+$ $68+60+62+58+54+72+66+51) / 2=281]$.

5.2. Variables and Symbols Definition. Definitions of variable and symbol are detailed in the Table 5:

(i) $Y=$ total passenger ship crew.

(ii) $F=$ full-time crew (all work during the period 9:00 a.m. through 21:00 p.m.).

(iii) $P_{1}$ to $P_{13}=$ part-time crew.

5.3. Modeling and Explanation. The LPs model is written as follows:

$$
\operatorname{Min} Y=F+\sum_{i=1}^{13} P_{i}
$$

(1) Part-time crew hours cannot exceed $50 \%$ of the day's minimum requirement:

$$
\begin{gathered}
6\left(P_{1}+P_{2}+P_{3}+P_{4}+P_{5}+P_{6}+P_{7}+P_{8}+P_{9}\right. \\
\left.+P_{10}+P_{11}+P_{12}+P_{13}\right) \leq 281 .
\end{gathered}
$$

(2) Minimal number of crew during 6-8:

$$
P_{1}+P_{2} \geq 71
$$

(3) Minimal number of crew during 8-10:

$$
F+P_{1}+P_{2}+P_{3}+P_{4} \geq 68 \text {. }
$$

(4) Minimal number of crew during 10-12:

$$
0.5 F+P_{1}+P_{2}+P_{3}+P_{4}+P_{5}+P_{6} \geq 60 \text {. }
$$

(5) Minimal number of drivers crew during 12-14:

$$
0.5 F+P_{1}+P_{2}+P_{3}+P_{4}+P_{5}+P_{6}+P_{7} \geq 62 \text {. }
$$

(6) Minimal number of crew during 14-16:

$$
F+P_{4}+P_{5}+P_{6}+P_{7}+P_{8}+P_{9}+P_{10} \geq 58 .
$$

(7) Minimal number of crew during 16-18:

$$
F+P_{6}+P_{7}+P_{8}+P_{9}+P_{10}+P_{11}+P_{12} \geq 54 .
$$

(8) Minimal number of crew during 18-20:

$$
F+P_{8}+P_{9}+P_{10}+P_{11}+P_{12}+P_{13} \geq 72 .
$$

(9) Minimal number of crew during 18-20:

$$
P_{10}+P_{11}+P_{12}+P_{13} \geq 66 \text {. }
$$

(10) Minimal number of crew during 22-24:

$$
P_{12}+P_{13} \geq 51 \text {. }
$$

(11) Available number of the full-time crew is at most 106:

$$
F \leq 106 \text {, }
$$

where $F, P_{1}, P_{2}, P_{3}, \ldots, P_{11}, P_{12}, P_{13} \in Z^{+}$.

5.4. Computational Results. The model includes a series of LPs at nine different two-hour time intervals. First, we run the LP using the largest passenger number and the maximum transit time and the data from the previous optimizing result, at the nine two-hour time intervals. We select the maximum number of passenger ships provided to match the passenger demand all the day at each depot. The optimal number of full-time crew is 60, and part-time crew is 46 . Passenger ship companies advise that the current number of full time crew under way is 85 . The fleet size of the passenger ship crews can be reduced by $29.4 \%$.

\section{Discussion and Conclusions}

This paper develops several mathematical models to optimize the fleet size of passenger ships and crew members. Optimization reduces the fleet size of passenger ships from 93 to 72 by $22.6 \%$. A series of LPs models is developed to show that the current fleet size of passenger ship crew members can be reduced from 85 to 60 by $29.4 \%$. This optimization would significantly lower both the operating costs of the shipping companies and traffic pressure of Macau.

We need to consider the impact of passengers' tolerance for waiting time. We can examine this through sensitivity analysis. Using Sheung Wan as one example, if the tolerance upper limit is reduced to 12 minutes, the number of the passenger ships from Sheung Wan to Ferry Terminal will increase to 5 . The number of passenger ships from Ferry Terminal to Sheung Wan will increase from 3 to 5. The optimal number of the passenger ships of these shipping companies will be 88 . The fleet size of the passenger ships will increase by 8 if the tolerance limit of the waiting time reduces by one minute. 
TABLE 4: The minimal number of drivers of each period.

\begin{tabular}{lccccccccc}
\hline Time & $6-8$ & $8-10$ & $10-12$ & $12-14$ & $14-16$ & $16-18$ & $18-20$ & $20-22$ & $22-24$ \\
\hline Number & 71 & 68 & 60 & 62 & 58 & 54 & 72 & 66 & 51 \\
\hline
\end{tabular}

TABLE 5: The definition of variable and symbol of PS crews.

\begin{tabular}{|c|c|c|c|}
\hline $\begin{array}{l}\text { The total number } \\
\text { of PS crews }\end{array}$ & & $Y$ & \\
\hline $\begin{array}{l}\text { The number of } \\
\text { full-time crews }\end{array}$ & $\begin{array}{c}\text { Working } \\
\text { hours }\end{array}$ & $\begin{array}{c}\text { The number } \\
\text { of part-time } \\
\text { crews }\end{array}$ & Working hours \\
\hline \multirow{13}{*}{$F$} & \multirow{13}{*}{ 9:00-21:00 } & $P_{1}$ & $6: 00-12: 00$ \\
\hline & & $P_{2}$ & $7: 00-13: 00$ \\
\hline & & $P_{3}$ & 8:00-14:00 \\
\hline & & $P_{4}$ & 9:00-15:00 \\
\hline & & $P_{5}$ & 10:00-16:00 \\
\hline & & $P_{6}$ & 11:00-17:00 \\
\hline & & $P_{7}$ & $12: 00-18: 00$ \\
\hline & & $P_{8}$ & 13:00-19:00 \\
\hline & & $P_{9}$ & $14: 00-20: 00$ \\
\hline & & $P_{10}$ & $15: 00-21: 00$ \\
\hline & & $P_{11}$ & $16: 00-22: 00$ \\
\hline & & $P_{12}$ & $17: 00-23: 00$ \\
\hline & & $P_{13}$ & 18:00-24:00 \\
\hline
\end{tabular}

Passenger ships have VIP, luxury, and standard cabins. Most passengers do not choose VIP and luxury cabins on a short journey. Our paper assumes that all passengers only consider the standard cabin. If this assumption does not hold, the capacity of passenger ships at 415 seats should be adjusted, and further research will resolve to solve this issue.

\section{Conflict of Interests}

The authors would like to declare that there is no conflict of interests regarding the publication of this paper.

\section{References}

[1] G. E. Bijwaard and S. Knapp, "Analysis of ship life cycles-the impact of economic cycles and ship inspections," Marine Policy, vol. 33, no. 2, pp. 350-369, 2009.

[2] AMCM, Economic Statistics from Monetary Authority of Macau, 2012.

[3] DSEC, DSEC - for the Current Data of Visitor Arrivals by Place of Residence, 2012.

[4] M. Hub, "Macau expected to receive between 34 and 35 million tourists in 2013," 2013.

[5] K. Theodore, "German travel trade give most promising destination award to Macau," Travel Daily News, 2007.

[6] The Organization of World Tourism, "World's top tourism destinations-top 25," 2007.

[7] M. Christiansen, K. Fagerholt, and D. Ronen, "Ship routing and scheduling: status and perspectives," Transportation Science, vol. 38, no. 1, pp. 1-18, 2004.
[8] M. Christiansen, K. Fagerholt, B. Nygreen, and D. Ronen, "Ship routing and scheduling in the new millennium," European Journal of Operational Research, vol. 228, no. 3, pp. 467-483, 2013.

[9] G. B. Dantzig and D. R. Fulkerson, "Minimizing the number of tankers to meet a fixed schedule," Naval Research Logistics Quarterly, vol. 1, no. 3, pp. 217-222, 1954.

[10] D. I. Jaramillo and A. N. Perakis, "Perakis, Fleet deployment optimization for liner shipping," Maritime Policy \& Management, vol. 18, no. 4, pp. 235-262, 1991.

[11] S. S. Cho and A. N. Perakis, "Optimal liner fleet routing strategies," Maritime Policy \& Management, vol. 23, no. 3, pp. 249-259, 1996.

[12] K. Fagerholt, "Optimal fleet design in a ship routing problem," International Transactions in Operational Research, vol. 6, no. 5, pp. 453-464, 1999.

[13] H. B. Bendall and A. F. Stent, "A scheduling model for a high-speed containership service: a hub and spoke short-sea application," International Journal of Maritime Economics, vol. 3, no. 3, pp. 262-277, 2001.

[14] A. K. Y. Ng and J. K. Y. Kee, "The optimal ship sizes of container liner feeder services in Southeast Asia: a ship operator's perspective," Maritime Policy \& Management, vol. 35, no. 4, pp. 353-376, 2008.

[15] Q. Meng and T. Wang, "A chance constrained programming model for short-term liner ship fleet planning problems," Maritime Policy \& Management, vol. 37, no. 4, pp. 329-346, 2010.

[16] M. Crary, L. K. Nozick, and L. R. Whitaker, "Sizing the US destroyer fleet," European Journal of Operational Research, vol. 136, no. 3, pp. 680-695, 2002.

[17] S.-C. Ting and G.-H. Tzeng, "Ship scheduling and cost analysis for route planning in liner shipping," Maritime Economics \& Logistics, vol. 5, no. 4, pp. 378-392, 2003.

[18] M. F. Lai and H. K. Lo, "Ferry service network design: optimal fleet size, routing, and scheduling," Transportation Research. Part A. Policy and Practice, vol. 38, no. 4, pp. 305-328, 2004.

[19] K. Fagerholt, "Designing optimal routes in a liner shipping problem," Maritime Policy and Management, vol. 31, no. 4, pp. 259-268, 2004.

[20] T. Richir, J.-D. Caprace, N. Losseau, E. Pircalabu, C. Toderan, and P. Rigo, "Least cost optimization of large passenger vessels," Ships and Offshore Structures, vol. 2, no. 4, pp. 339-345, 2007.

[21] Q. Zeng and Z. Yang, "Model integrating fleet design and ship routing problems for coal shipping," in Computational ScienceICCS 2007, vol. 4489 of Lecture Notes in Computer Science, pp. 1000-1003, 2007.

[22] K. Fagerholt and H. Lindstad, "TurboRouter: an interactive optimisation-based decision support system for ship routing and scheduling," Maritime Economics \& Logistics, vol. 9, no. 3, pp. 214-233, 2007.

[23] K. Fagerholt, M. Christiansen, L. Magnus Hvattum, T. A. V. Johnsen, and T. J. Vabø, "A decision support methodology for strategic planning in maritime transportation," Omega, vol. 38, no. 6, pp. 465-474, 2010. 
[24] K. Fagerholt, T. A. V. Johnsen, and H. Lindstad, "Fleet deployment in liner shipping: a case study," Maritime Policy and Management, vol. 36, no. 5, pp. 397-409, 2009.

[25] P. G. Zacharioudakis, S. Iordanis, D. V. Lyridis, and H. N. Psaraftis, "Liner shipping cycle cost modelling, fleet deployment optimization and what-if analysis," Maritime Economics \& Logistics, vol. 13, no. 3, pp. 278-297, 2011.

[26] X. Liu, H.-Q. Ye, and X.-M. Yuan, "Tactical planning models for managing container flow and ship deployment," Maritime Policy \& Management, vol. 38, no. 5, pp. 487-508, 2011.

[27] J. F. Alvarez, P. Tsilingiris, E. S. Engebrethsen, and N. M. Kakalis, "Robust fleet sizing and deployment for industrial and independent bulk ocean shipping companies," INFOR, vol. 49, no. 2, pp. 93-107, 2011.

[28] Service Route, Onboard Service and Facilities of Turbojet, Shun Tak-China Travel Ship Management Limited, 2007.

[29] Y. D. Shi, H. J. Tang, H. C. Zhang, X. Y. Hu, and B. Sun, "Study on the optimal operation of free shuttle buses in Macau," Journal of Macau University of Science and Technology, vol. 4, pp. 37-46, 2010. 


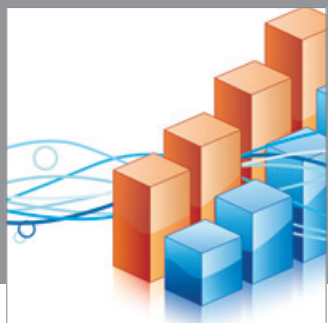

Advances in

Operations Research

mansans

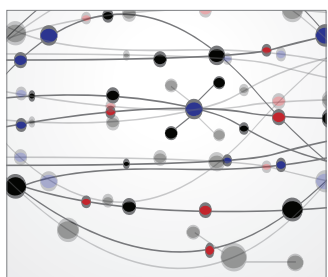

The Scientific World Journal
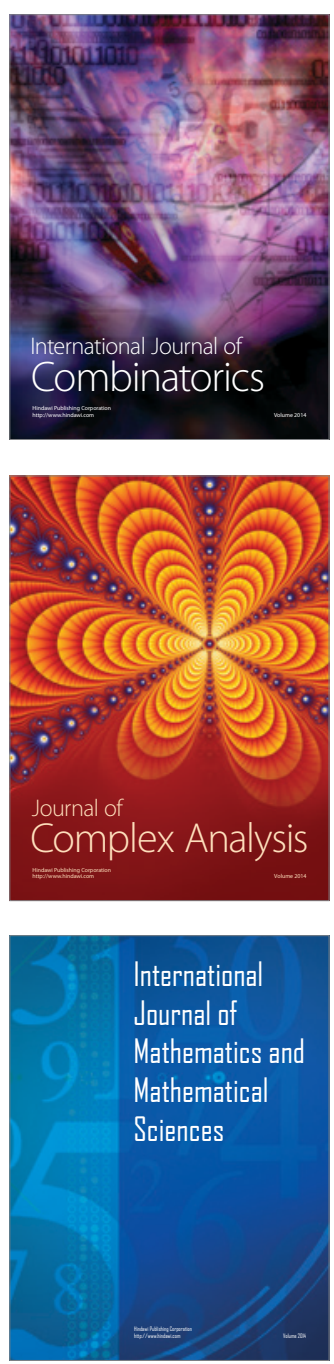
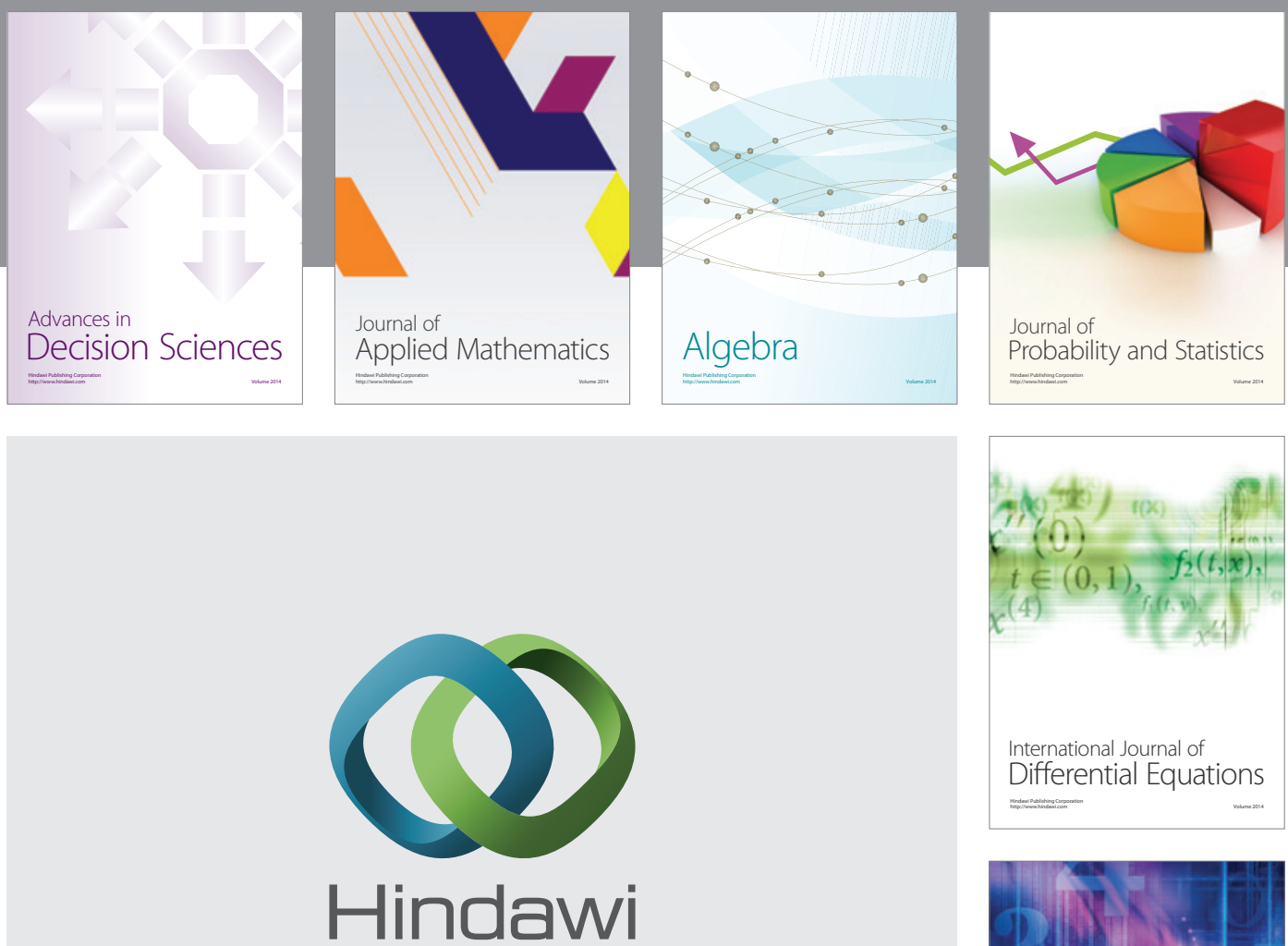

Submit your manuscripts at http://www.hindawi.com
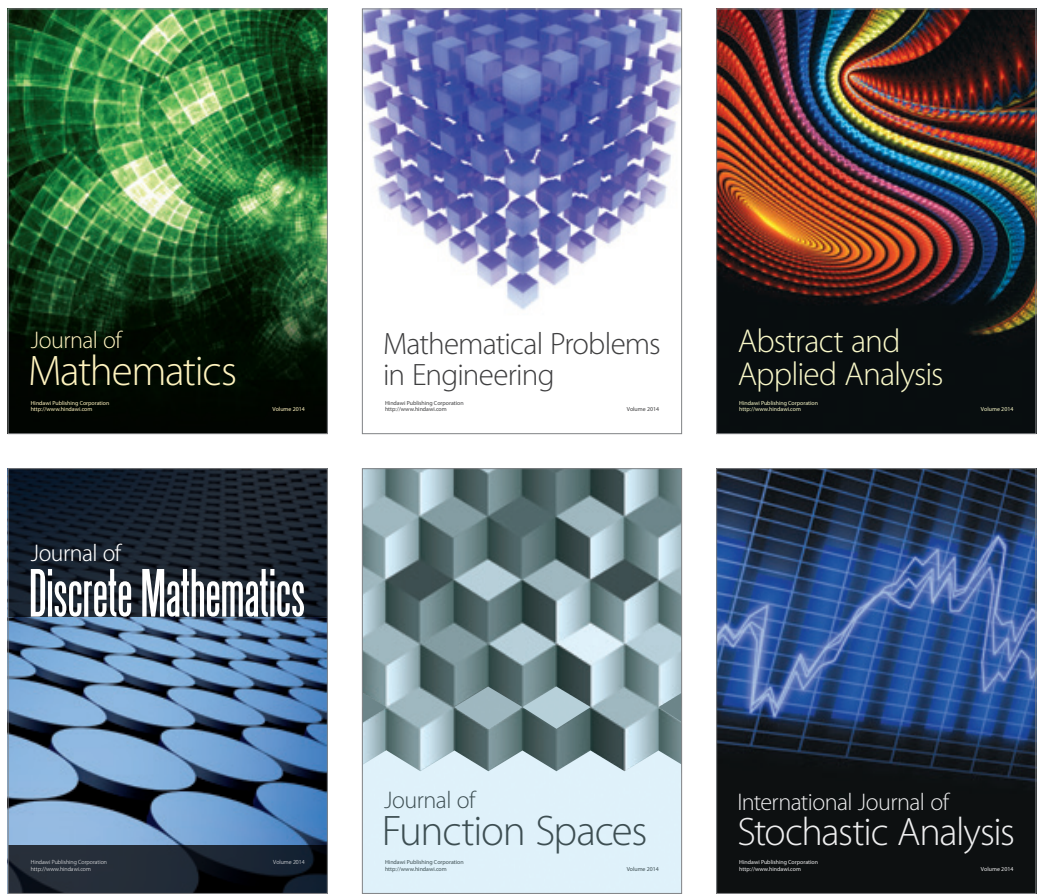

Journal of

Function Spaces

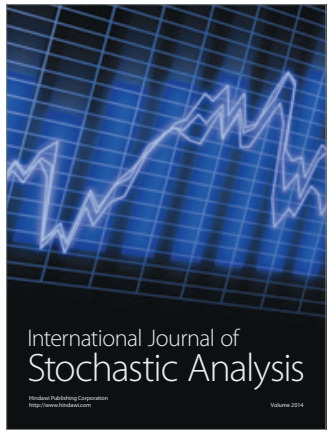

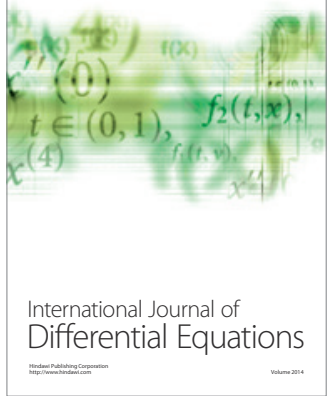
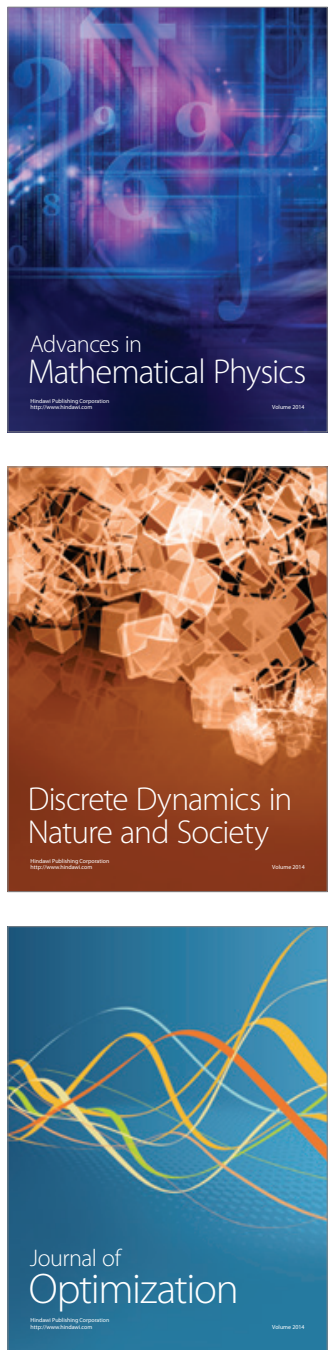